\title{
The Ti6Al4V Alloy Microstructure Modification Via Various Cooling Rates, its Influence on Hardness and Microhardness
}

Juraj Belan, Milan Uhríčik, Patrícia Hanusová, Alan Vaško

Faculty of Mechanical Engineering, University of Žilina. Univerzitná 8215/1, 01026 Žilina. Slovak Republic. Email: juraj.belan@fstroj.uniza.sk

Titanium alloy Ti6Al4V falls into the group of $\alpha-\beta$ titanium alloys and its widely used for engineering application due to its unique mechanical properties in regular or corrosion environments. Mechanical properties of alloy are strictly depending on final microstructure. The microstructure can be varying by various heat-treatment procedures. Heating slightly over $\beta$-transus temperatures, $1050^{\circ} \mathrm{C}$, with a dwell of 3 hours and cooling by various rates provide a wide possibility of microstructure modification. The cooling rates were represented by water quenching, air cooling, and furnace cooling. The microstructure has changed from lamellar $\alpha$-phase in prior $\beta$-grains, through Widmanstätten microstructure to lamellar $\alpha^{\prime}$ martensite structure due to cooling rates. After applied heat-treatment, the Vickers hardness HV10/10 (STN EN ISO 6507) and Vickers microhardness HV0.2/10 (STN EN ISO 6507) were done. The hardness and microhardness test results were compared to the starting stage. The Vickers hardness increases in all states about $8 \%$ for furnace cooling, $18 \%$ for air cooling, and almost $40 \%$ for water quenching. The same situation was for Vickers microhardness which increases about almost $29 \%$ for furnace cooling, $16 \%$ for air cooling, and $25 \%$ for water quenching. The hardness measurement shows increasing mechanical properties after all cooling rates. However, heat-treatment also shows negatives by creating the $\alpha$ case layer and surface cracks, which is negative for the fatigue life of Ti6Al4V alloy.

Keywords: Ti6Al4V Alloy, $\beta$-transus Annealing, Various Cooling Rates, Microstructure Modification, Vickers Hardness, Vickers Microhardness

\section{Introduction}

Titanium and its alloys are characterized by high strength, low weight ratio and excellent corrosion resistance. These properties predispose titanium alloys to a wide and diverse range of successful applications that require high reliability, e.g. in surgery and medicine, in the aerospace, automotive, chemical, energy, oil and gas, sports and other major industries. In most of these and other technical applications, titanium alloys have replaced materials with less favourable weight ratios, lower reliability, or cheaper materials [13]. The unique mechanical properties of titanium alloys, which meet the requirements of progressive and modern designs, make it possible to create reliable, cost-effective and more durable systems and components that in many situations have significantly exceeded performance and durability expectations $[4,5]$.

The microstructure of titanium alloys strictly depends on chemical composition. According to elements alloying the titanium alloys may be divided into following groups [2]:

- $\quad \alpha$ and near $\alpha$ - alloys (stabilising elements are $\mathrm{Al}, \mathrm{O}, \mathrm{N}, \mathrm{C})$,

- $\quad \alpha+\beta$ alloys (combination of $\alpha$ stabilising and $\beta$ stabilising elements),
- $\beta$ and metastable $\beta$ - alloys (stabilising elements are $\mathrm{V}, \mathrm{Mo}, \mathrm{Ta}, \mathrm{Nb}, \mathrm{Fe}, \mathrm{Mn}, \mathrm{Cr}, \mathrm{Co}, \mathrm{Ni}$, $\mathrm{Cu}, \mathrm{Si}, \mathrm{H})$.

Titanium Ti6Al4V (Grade 5) alloy falls into $\alpha+\beta$ alloy group and provides an excellent physical and mechanical properties which can be improved and modified by heat-treatment. The Ti6Al4V mechanical properties and fatigue life [6] are related to final alloy microstructure. The most common microstructures for Ti6Al4V alloy are lamellar microstructure created when cooled from over $\beta$-transus temperatures and equiaxed microstructure as a result of recrystallization.

After heat-treatment the Widmanstätten microstructure may be observed when alloy is cooled down by critical rate. Ohmori et al. [7] has described the mechanism of $\alpha$-Widmanstätten microstructure formation in Ti6Al4V alloy. They found out, that $\alpha$-Widmanstätten laths start to form isothermally on prior $\beta$ grains boundary at transformation temperature from $\beta$-transus to around $950^{\circ} \mathrm{C}$ and continuously growing with decreasing of transformation temperature till $700^{\circ} \mathrm{C}$. The $\alpha$-Widmanstätten lath thickness also decreasing from $1.8 \mu \mathrm{m}$ at transformation temperature 
$925^{\circ} \mathrm{C}$ to 0.4 at transformation temperature $775^{\circ} \mathrm{C}$. Ahmed and Rack [8] in their work have described phase transformation in Ti6Al4V alloy related to cooling rates. They show that $\alpha$-Widmanstätten is formed by diffusion controlled mechanism at cooling rates < $20^{\circ} \mathrm{C} . \mathrm{s}^{-1}$, at cooling rates between $20^{\circ} \mathrm{C} . \mathrm{s}^{-1}$ and

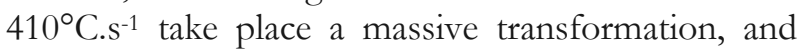
cooling rates above $410^{\circ} \mathrm{C} . \mathrm{s}^{-1}$ are necessary to form fully $\alpha^{\prime}$-martensitic microstructure.

Forming the Widmanstätten (or basket-weave) microstructure has moderate influence on mechanical properties such tensile strength (UTS), $0.2 \%$ yield strength (YS) and ductility. Gil et al. [9] reports that slow cooling rates which forms $\alpha$-Widmanstätten microstructure have no significant influence on UTS, $0.2 \% \mathrm{YS}$, and ductility. However, when higher cooling rates are applied (water quenching) the Widmanstätten lamellae transforms into $\alpha^{\prime}$-martensite microstructure and UTS, $0.2 \% \mathrm{YS}$ are dramatically increased and ductility decreases. Wu et al. [10] discussed the microstructure evolution of selective-laser melted Ti6Al4V alloy after post heat-treatments on Vickers hardness. They concluded that Vickers hardness increases with increasing post heat-treatment temperature and the maximum value $422 \pm 2.8 \mathrm{HV}$ was obtained at $500^{\circ} \mathrm{C}$.
Our goal was evaluating the influence of various cooling rates on microstructure and Vickers hardness and microhardness of Ti6Al6V wrought alloy. The heat-treatment temperature was $1050^{\circ} \mathrm{C}$ with dwell of 3 hours and followed by cooling in cold water (water quenching), air, and furnace. This cooling rates should represent three various microstructures. The lamellar $\alpha$-phase in prior $\beta$-grains with basket-weave $\alpha$-phase microstructure at $\beta$-grains interface formation when furnace cooling, forming the $\alpha$-Widmanstätten structure when air cooled, and finally the fully $\alpha^{\prime}$-martensite structure when water quenched. Vickers hardness and microhardness measurements were done and obtained results were compared to alloy in starting stage.

\section{Experimental material and methods}

The blocky shape specimens with dimensions 10 $\mathrm{mm} \times 11 \mathrm{~mm} \times 55 \mathrm{~mm}$, made from wrought Ti6Al4V alloy was used as an experimental material. The specimens were supplied by BIBUS Metals AG, Brno, CZ. The chemical composition (in wt.\%) obtained by optical emission spectrometer SpectroMAXx (own measurement) and HV hardness value (according to supplier's material list HX-032) are in Tab. 1. Specimens were only in annealed conditions.

Tab. 1 The Ti6 Al4V chemical composition in mass volume and HV hardness value.

\begin{tabular}{|c|c|c|c|c|c|c|c|c|}
\hline 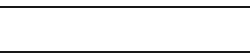 & $\mathrm{Fe}$ & C & $\mathbf{N}$ & $\mathbf{H}$ & $\mathbf{O}$ & $\mathrm{Al}$ & $\mathrm{V}$ & $\mathrm{Ti}$ \\
\hline BIBUS & 0.059 & 0.012 & 0.0044 & 0.001 & 0.097 & 6.04 & 4 & Balance \\
\hline \multirow{4}{*}{$\begin{array}{l}\text { SpectroMAXx } \\
\text { results }\end{array}$} & $\mathrm{Fe}$ & C & $\mathbf{N}$ & $\mathbf{H}$ & $\mathbf{O}$ & Al & V & $\mathrm{Ti}$ \\
\hline & 0.0967 & 0.0259 & - & - & - & 6.32 & 4.43 & 89.0 \\
\hline & Sn & Si & Mn & $\mathrm{Cr}$ & $\mathrm{Cu}$ & $\mathrm{Nb}$ & & \\
\hline & 0.0024 & 0.0259 & 0.0074 & 0.0041 & 0.0045 & 0.03 & & \\
\hline \multicolumn{9}{|c|}{ Hardness (HV) } \\
\hline \multicolumn{9}{|c|}{266} \\
\hline
\end{tabular}

Applied heat-treatment consisted of heating on temperature $1050^{\circ} \mathrm{C}$ to secure homogenous $\beta$-phase. The $\beta$-transus temperature for Ti6Al4V alloy is $995 \pm$ $5^{\circ} \mathrm{C}$. The dwell on this temperature was 3 hours, followed by cooling down in various environments: for slow cooling rate the furnace cooling (FC), medium cooling rate on air (AC), and water quenching (WQ) for fast cooling rates (over $\left.500^{\circ} \mathrm{C}_{\mathrm{s}} \mathrm{s}^{-1}\right)$.

For Vickers hardness measurements (according to STN EN ISO 6507 standard) was used HPO-250/AQ testing machine. Specimens surface were grained with 600 grain sandpaper and then polished with 3.2 diamond paste. The load used was $98.1 \mathrm{~N}$ and dwell time $10 \mathrm{~s}$ (HV10/10). The result hardness value was obtained from ten measurements on each specimens' state (FC, AC, and WQ). The Zwick / Roell ZH $\mu$ testing machine with load $1.961 \mathrm{~N}$ and dwell $10 \mathrm{~s}$ (HV0.2/10, according to STN EN ISO 6507 standard) was used for Vickers microhardness measurements. The result microhardness was obtained form
20 (alloy starting stage) measurements or 100 (for FC, AC, WQ alloy state) measurements, respectively.

Samples for metallographic analysis were hotpressed on a Struers Citopress 1. This was followed by grinding and polishing of the samples on a TegraPol15 machine from Struers. The program for titanium alloys consisted of 4 steps. The first was to grind the samples with 320 grit $\mathrm{SiC}$ sandpaper for 1 minute and 20 seconds. The samples were wetted with water during grinding. In the second step, the samples were gently ground on an MD Largo wheel and DiaPro Allergo / Largo paste for 5 minutes. The third step was to polish the samples using an MD Dac wheel and DiaPro Dac paste for 3 minutes. The last step consisted of chemical polishing using an MD Chem wheel and OP - S paste and took 3 minutes [11]. Between steps, samples were rinsed with warm water, alcohol and dried. Finally, the samples were etched with $10 \% \mathrm{HF}$ or an etchant consisting of $1.5 \mathrm{ml} \mathrm{HF}+2 \mathrm{ml} \mathrm{HNO}_{3}$ $+10 \mathrm{ml} \mathrm{H}_{2} \mathrm{O}$. The sample was immersed in the etch- 
ant for approx. 7 seconds, then rinsed with water, alcohol and dried. After preparation were the specimens observed by optical microscope NEOPHOT 32 and SEM Tescan Vega LMU II.

\section{Results and discussion}

The microstructure of the titanium alloy Ti6Al4V in the initial state is formed by columnar grains of the original $\beta$-phase in which $\alpha$-phase lamellae are excluded, Fig. 1a. The $\alpha$-phase, in this case, is oriented in different directions in one grain of the original $\beta$ phase and thus creates a typical microstructure of the wrought, dual phase annealed alloy.

The microstructure of the alloy after applied heat
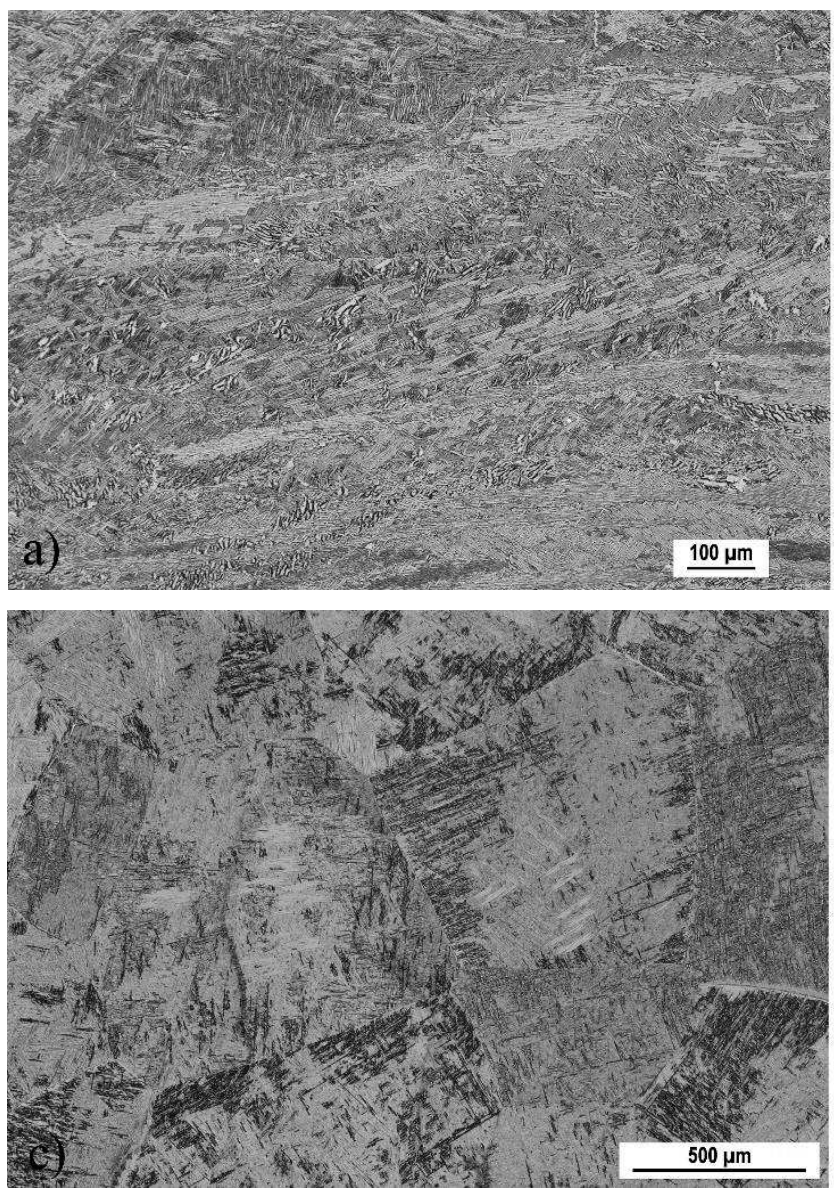

treatment, heating to $1050^{\circ} \mathrm{C}$, holding for 3 hours and cooling in various environments is shown in Fig. 1bd. Depending on the cooling rate, significant changes in the microstructure occur. In the case of the slowest cooling, represented by furnace cooling (FC), Fig. 1b, the microstructure is formed by a coarse polyedric grain of the $\beta$-phase and coarse lamellae of the $\alpha$ phase. At the $\beta$-phase grain boundaries, new $\alpha$-phase lamellae are formed by the mechanism shown in Fig. $2 \mathrm{a}$. The $\alpha$-phase at the $\beta$-grain boundaries first creates the zig-zag morphology and separate the $\beta_{1}$ and $\beta_{2}$ grains, which then grows in the form of lamellae inside the $\beta$-phase grain and thus creates the basket-weave structure.
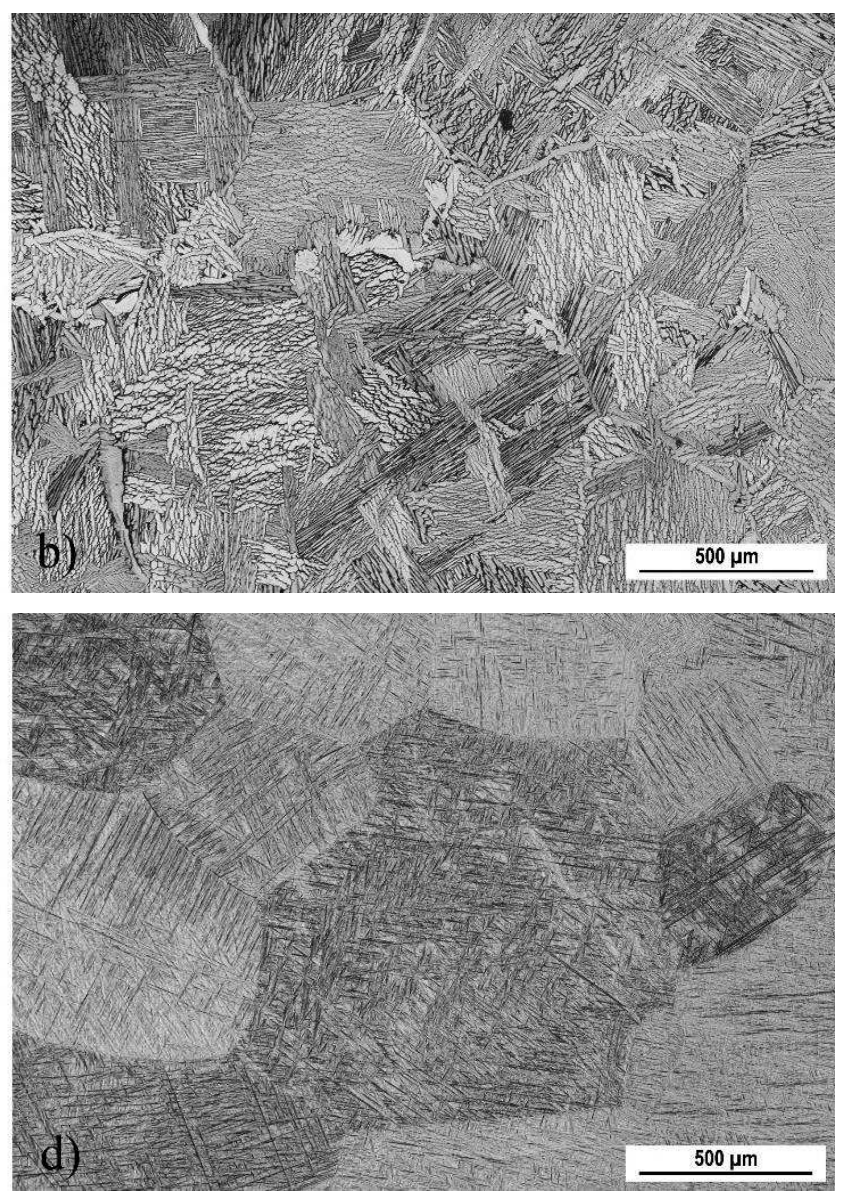

Fig. 1 Microstructures of Ti6 Al4V alloy; a) starting state with columnar $\beta$-phase grains, etch. $10 \% \mathrm{HF}$, b) coarse $\beta$-phase grains and basket-weave structure on $\beta$-grains boundary after $1050^{\circ} \mathrm{C} / 3 \mathrm{hrs} .-\mathrm{FC}$, etch. $1.5 \mathrm{ml} \mathrm{HF}+2 \mathrm{ml} \mathrm{HNO}+10 \mathrm{ml} \mathrm{H} \mathrm{H}_{2} \mathrm{O}-\mathrm{DIK}$, c) Widmanstätten microstructure formation with minor $\alpha^{\prime}$-martensite needles after $\mathrm{AC}$, etch. $1.5 \mathrm{ml} \mathrm{HF}+2 \mathrm{ml} \mathrm{HNO}+10 \mathrm{ml} \mathrm{H}_{2} \mathrm{O}$ - DIK, d) fully $\alpha^{\prime}$-martensite microstructure in coarse $\beta$-phase grains after $\mathrm{WQ}$, etch. $1.5 \mathrm{ml} \mathrm{HF}+2 \mathrm{ml} \mathrm{HNO}+10 \mathrm{ml} \mathrm{H}_{2} \mathrm{O}-$ DIK

The microstructure of the alloy after air cooling (AC) is shown in Fig. 1c. It is again formed by the coarse grain of the original $\beta$-phase. The lamellae of the $\alpha$-phase, due to the higher cooling rate, are narrower and longer what is in good correlation with results published in [7] and the original alpha phase is continuously transformed into an $\alpha$-Widmanstäten microstructure (via mechanism reported in Fig. 2b-c). Again, it is possible to observe $\alpha$-phase in basketweave structure at the boundaries of the original $\beta$ phase, which grows significantly inside into the $\beta$ phase grain. A minimum amount of $\alpha^{\prime}$-martensite can also be observed in certain areas.

As a result of the highest cooling rate, represented 
by cooling in water (WQ) with a cooling rate higher

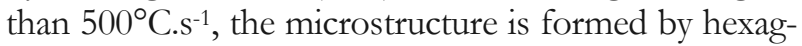
onal $\alpha^{\prime}$-martensite, Fig. 1d, segregated in the form of long needles. These $\alpha^{\prime}$-martensite needles are oriented either perpendicular or at an angle of approximately $45^{\circ}$ to the original $\beta$-phase boundary.

A secondary effect of the applied heat treatment was the formation of a significantly thickened microstructure on the surface of the samples with the massive segregation of the needle alpha phase as a consequence of the diffusion of oxygen on the surface of the alloy, Fig. 3a, b. In addition to the segregation of coarse alpha phase needles, significant cracks also appeared on the surface of the samples, Fig. 3c, which were created by internal stresses while increasing the volume of the $\alpha$-phase on the surface. These cracks follow the $\alpha / \beta$ phase interface. In some cases, a mechanical mixture of $\alpha$-phase and $\mathrm{Ti}_{3} \mathrm{Al}$ phase, which is found in the binary $\mathrm{Ti}-\mathrm{Al}$ system at temperatures above $1000^{\circ} \mathrm{C}$, was precipitated on the surface of the samples, Fig. 3d.
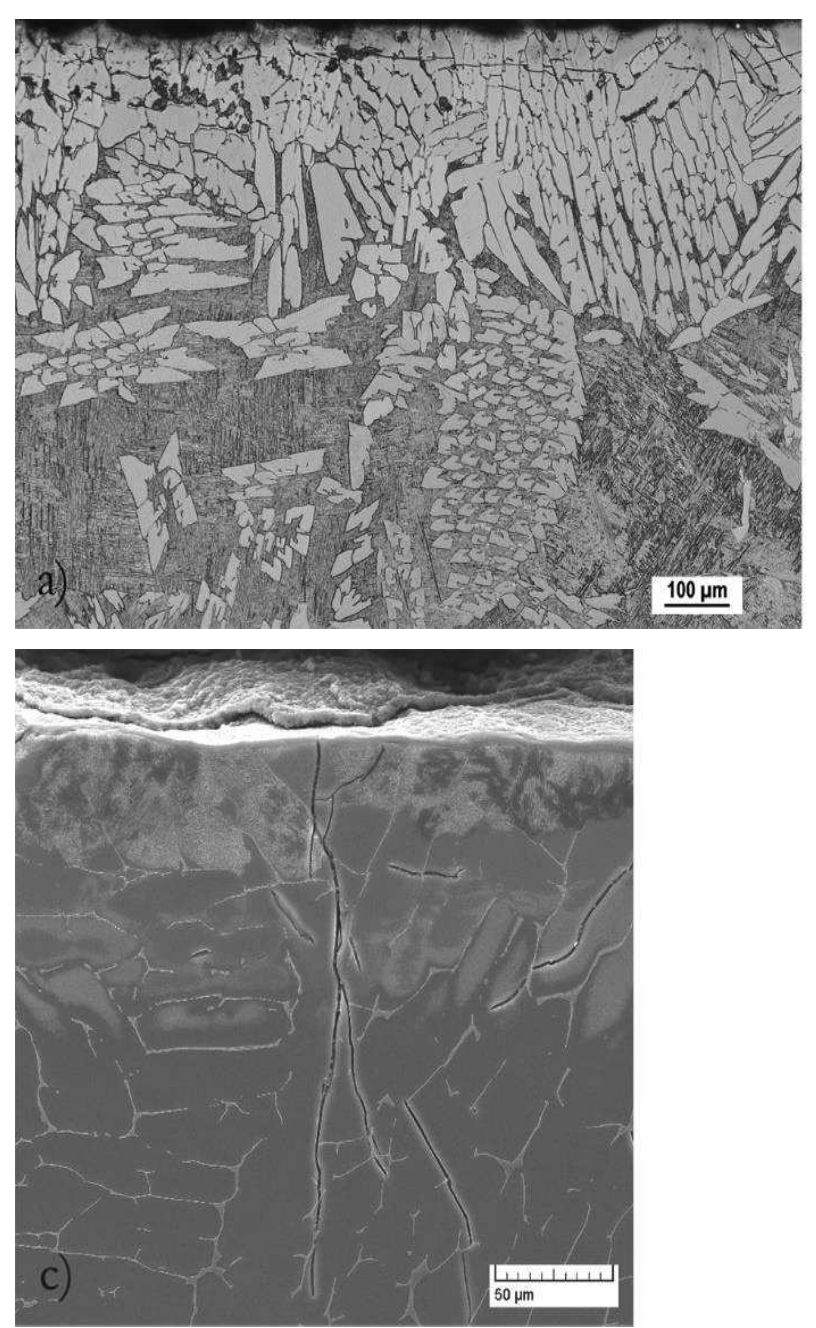

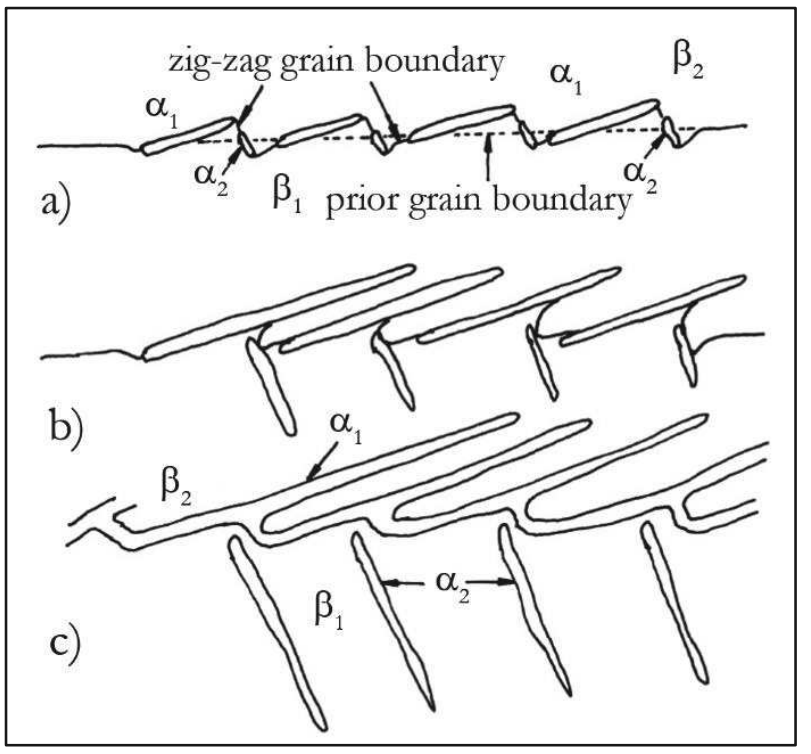

Fig. 2 Schematic illustration of Widmanstätten lath formation and growth; a) $\alpha$-phase nucleation on prior $\beta$-grains boundary, b) continuous growth of $\alpha$-phase lamellae, transforming to Widmanstätten structure, c) coalescence of $\alpha$-Widmanstätten structure, illustration adopted from ref. [7]
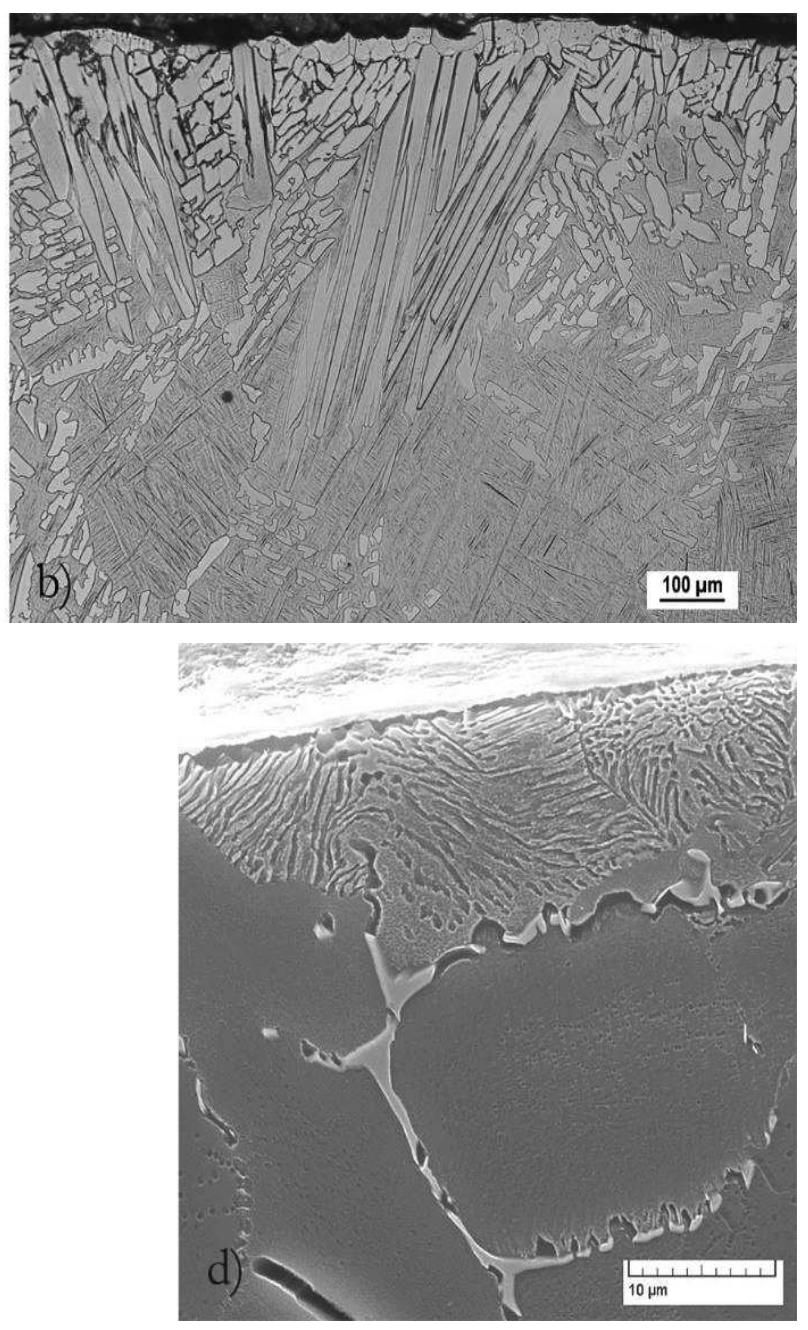

Fig. 3 A massive $\alpha$-phase segregation at specimens surface after heat-treating, a) specimen $A C$, b) specimen $W Q$ c) crack at $\alpha / \beta$ interphase boundary, and d) segregation of mechanical mixture of $\alpha$-phase + Ti, $\mathrm{Al}$ intermetallic compound, etch. $10 \% \mathrm{HF}$ 
The results of Vickers hardness and microhardness measurements with calculated standard deviation are given in Tab. 2. Microhardness measurements were obtained from matrix-distributed measurements. The size of the test matrix was $10 \times 10$ measurements, which included microhardness measurements just below the surface, in the region with massively segregated $\alpha$ phase, through the region from the coarsely $\beta$-phase to the recrystallized core of the sample. The measurement method is shown in Fig. 4 a-c.

Tab. 2 Vickers hardness and microhardness measurements results with calculated standard deviation and HV10/10 and HV0.2/10 percentage difference compared to starting stage.

\begin{tabular}{|l|l|l|c|c|}
\hline Hardness & HV10/10 & HV0.2/10 & $\begin{array}{l}\text { HV10/10 difference } \\
\text { compared to St. S. [\%] }\end{array}$ & $\begin{array}{l}\text { HV0.2/10 difference } \\
\text { compared to St. S. [\%] }\end{array}$ \\
\hline Staring stage (St. S.) & $346.6 \pm 20.9$ & $367.55 \pm 21.1$ & - & - \\
\hline $\mathbf{1 0 5 0}^{\circ} \mathbf{C} / 3$ hrs. - FC & $374.4 \pm 20.1$ & $474.0 \pm 24.5$ & $+8.0 \%$ & $+28.9 \%$ \\
\hline $\mathbf{1 0 5 0}^{\circ} \mathbf{C} / 3$ hrs. - AC & $409.2 \pm 10.4$ & $426.0 \pm 20.9$ & $+18.0 \%$ & $+15.9 \%$ \\
\hline $\mathbf{1 0 5 0}^{\circ} \mathbf{C} / 3$ hrs. - WQ & $485.0 \pm 11.9$ & $459.2 \pm 18.5$ & $+39.9 \%$ & $+24.9 \%$ \\
\hline
\end{tabular}
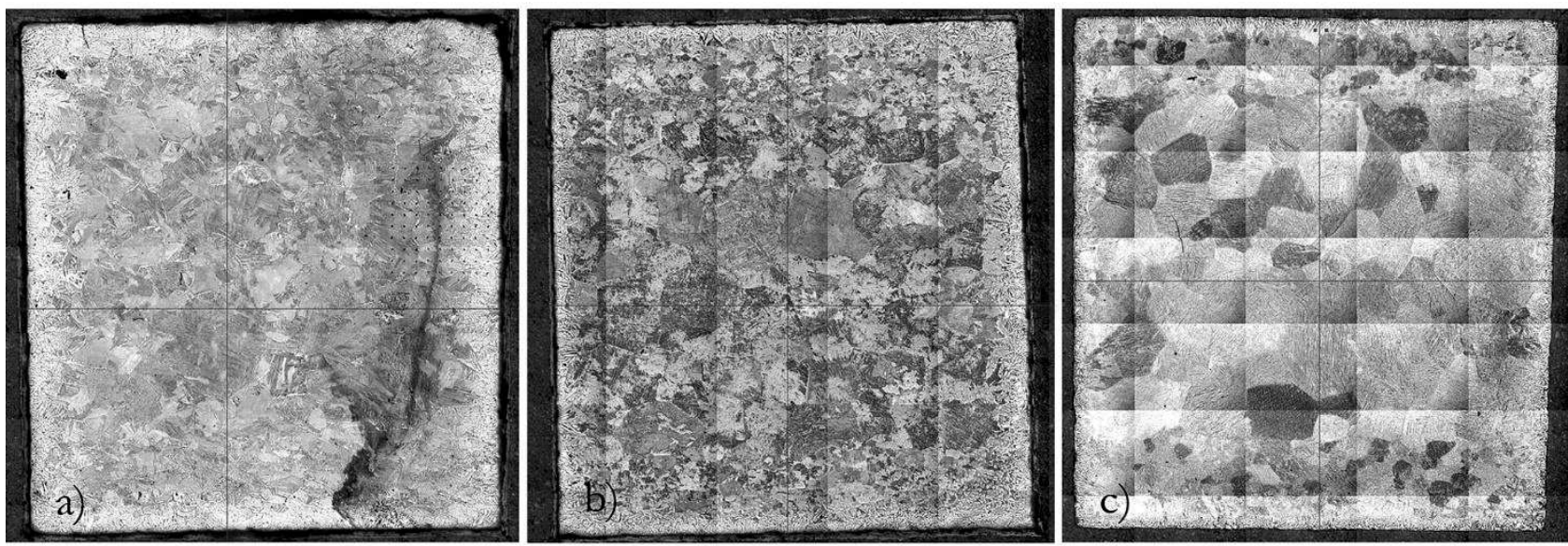

Fig. 4 Microhardness measurements matrix for specimens after, a) AC, b) FC, and c) WQ

Based on the results of the hardness measurement, we can state that the hardness increases with increasing cooling rate, where the maximum values were reached at WQ and with the structure fully formed by $\alpha^{\prime}$-martensite, which is in good agreement with the results of Jovanivić et al. [12]. It is also possible to assume that the UTS will change in the same way. Thus, the highest strength will be achieved with an $\alpha^{\prime}$-martensitic structure.

\section{Conclusion}

Titanium Ti6Al4V wrought alloy with dual $\alpha+\beta$ microstructure was used as experimental material for study the effect of cooling rate on the resulting microstructure and hardness of the alloy. Samples of this alloy were heat treated by heating to a temperature above $\beta$-transus $\left(1050^{\circ} \mathrm{C}\right)$ with a dwell time of 3 hours and subsequent cooling in various media. These media represented different cooling rates, furnace cooling (FC) was the slowest rate, mean cooling rate was represented by air cooling (AC), and the fastest cooling rate (greater than $500^{\circ} \mathrm{C} . \mathrm{s}^{-1}$ ) was when cooled to water (WQ). Based on the above, we can formulate conclusions:
- the microstructure at starting stage was formed by $\beta$-phase columnar grains with $\alpha$ phase lamellae,

- with increasing cooling rate, the microstructure changed from a lamellar $\alpha$ phase (in FC cooling), through an $\alpha$-Widmanstätten in AC cooling to an $\alpha^{\prime}$-martensitic in WQ,

- as a secondary result, the precipitation of coarse $\alpha$-phase needles on the surface of the samples after heat treatment resulted in cracks at the $\alpha / \beta$ interface,

- with the increasing of cooling rate, the hardness and microhardness as well of the samples also increased, where the highest value of hardness was reached at WQ samples, HV10/10 = $485 \pm 11.9$ and microhardness HV0.2/10 = 459.2 \pm 18.5 ,

- the presence of a fully martensitic structure, with a high proportion of $\alpha^{\prime}$-martensite needles, was thus reflected in an increase in the 
HV10/10 hardness value by $39.9 \%$ compared to the starting stage and an increase in the HV0.2/10 microhardness by $24.9 \%$ compared to the starting stage.

\section{Acknowledgement}

This work was supported under the project of $O p$ erational Program Research and Innovation: Research and development activities of the University of Žilina in the Industry of 21st century in the field of materials and nanotechnologies, No. 313011T426. The project is co-funding by the European Regional Development Fund. The authors also acknowledge the KEGA projects $016 \check{Z} U-4 / 2020$ and $012 \check{Z} U-4 / 2019$ for the financial support of this work.

\section{References}

[1] DONACHIE, M., J. (2000). Titanium: A Technical Guide. 2nd ed., p. 216. ASM International: Materials Park, Ohio, USA. ISBN 0-87170-6865

[2] LEYENS, C., PETERS, M. (2003). Titanium and Titanium Alloys. Fundamentals and Applications, p. 513. WILEY-VCH Verlag GmbH \& Co. KGaA, Weinheim, DE. ISBN 3-527-30534-3

[3] MOISEYEV, V., N. (2006) Titanium alloys: Russian Aircraft and Aerospace Applications vol 5, p. 207. CRC Press Taylor \& Francis, Boca Raton, USA. ISBN 0-8493-3273-7

[4] HANUSOVÁ, P., PALČEK, P., UHRIČÍK, M. (2019). Analysis of the Cause of Titanium Endoprosthesis Failure. Manufacturing Technology, Vol 19, No. 5, pp. 749 - 752, J. E. Purkyne University in Ústí nad Labem, CZ. ISSN 12132489

[5] FOUSOVÁ, M., VOJTĚCH, D., KUBÁSEK, J. (2016). Titanium Alloy Ti6Al4V Prepared by Selective Laser Melting (SLM). Manufacturing Technology, Vol 16, No. 4, pp. 691 - 697, J. E. Purkyne University in Ústí nad Labem, CZ. ISSN 1213-2489

[6] BELAN, J., KUCHARIKOVÁ, L., TILLOVÁ, E., CHALUPOVÁ, M. (2019). Three-point
Bending Fatigue Test of Ti6Al4V Titanium Alloy at Room Temperature. Advances in Materials Science and Engineering, Vol. 2019, pp. 1 - 12, Hindawi. ISSN 1687-8434

[7] OHMORI, Y., NAKAI, K., OHTSUBO, H., TSUNOFURI, M. (1994). Formation of Widmanstätten Alpha Structure in a Ti6Al4V alloy. Materials Transactions, JIM, Vol. 35, No. 4, pp. 238 - 246, The Japan Institute of Metals, Japan. ISSN 0916-1821

[8] AHMED, T., RACK, H., J. (1998). Phase Transformation During Cooling in $\alpha+\beta$ Titanium Alloys. Materials Science and Engineering: $A$, Vol. 243, No. 1-2, pp. 206 - 211, Elsevier B.V. ISSN 0921-5093

[9] GIL, F., J., GINEBRA, M., P., MANERO, J., M., PLANELL, J., A. (2001). Formation of $\alpha-$ Widmanstätten structure: effects of grain size and cooling rate on the Widmanstätten morphologies and on the mechanical properties in Ti6Al4V alloy. Joumal of Alloys and Compounds, Vol. 329, No. 1-2, pp. 142 - 152. Elsevier Science B. V. ISSN 0925-8388

[10] WU, S., Q., LU, Y., J., GAN, Y., L., HUANG, T., T., ZHAO, C., Q., LIN, J., J., GUO, S., LIN, J., X. (2016). Microstructural Evolution and Microhardness of a Selective-Laser-Melted Ti6Al4V Alloy After Post Heat-Treatments. Journal of Alloys and Compounds, Vol. 672, No. 5, pp. 643 - 652. Elsevier B.V. ISSN 0925-8388

[11] ZÁVODSKÁ, D., TILLOVÁ, E., KUCHARIKOVÁ, L., CHALUPOVÁ, M. (2016). Fractography Evaluation of Fracture Surfaces of Aluminium Alloy After Fatigue Tests. Manufacturing Technology, Vol 1, No. 5, pp. 1199 - 1204, J. E. Purkyne University in Ústí nad Labem, CZ. ISSN 1213-2489

[12] JOVANOVIĆ, M., T., TADIĆ, S., ZEC, S., MIŠKOVIĆ, Z., BOBIĆ, I. (2006). The Effect of Annealing Temperatures and Cooling Rates on Microstructure and Mechanical Properties of Investment Cast Ti-6Al-4V Alloy. Materials and Design, Vol. 27, No. 3, pp. 192 - 199, Elsevier B. V., ISSN 0261-3069 